\title{
Space representation in unilateral spatial neglect
}

\author{
F. CHEDRU \\ From the Hôpital de la Salpêtrière, Paris, France
}

SYNOPSIS Patients with unilateral brain lesions were given a task requiring exploration of space with the hand in order to assess the visual dependency of unilateral spatial neglect. The task was carried out both without visual control and under visual control. Performances were compared with that of normal subjects. Results were: (1) patients with right brain damage with no visual field defect demonstrated left-sided neglect only when the exploration was not controlled visually; (2) patients with left and right brain damage with visual field defect demonstrated contralateral neglect only when the exploration was under visual guidance. The performance of the patients with right brain damage without visual field defect is not clearly understood. The other results suggest that inner spatial representation remains intact in most cases of spatial neglect. The role of parietal lobe damage in the development of this visually induced phenomenon is hypothesised. The dominant position of vision among the senses is indicated.

Some brain-damaged patients demonstrate unilateral defects of space exploration (Brain, 1941; McFie et al., 1950; Benton, 1969; Oxbury et al., 1974). This phenomenon, known as unilateral spatial neglect, is generally studied through visual or visually controlled tasks, such as reading, visual searching or drawing. It is, therefore, uncertain whether the disorder is only visual or whether it corresponds to a basic disturbance of space representation. A priori an impairment in spatial representation is plausible as unilateral spatial neglect is often associated with non-visual signs of unilateral inattention-that is, tactile extinction, hemiasomatognosia-as well as with topographic memory loss, which appears to be a supramodal disorder (Semmes et al., 1955). Furthermore, according to a recent study, some brain damaged patients demonstrate spatial neglect in tests of tactile exploration (De Renzi et al., 1970). However, the latter experiment did not make clear whether or not an association exists between 'tactile' and 'visual' neglect, an association one might expect if the phenomenon resulted from disordered spatial representation. On the other hand, personal clinical observations suggested that, at least in some cases, spatial neglect could be dependent upon the visual channel. For example, patients with marked left-sided t:eglect were found to omit the

${ }^{1}$ Address for correspondence: Groupe de Recherches Neuropsychologiques, INSERM U84, Hôpital de la Salpêtrière, 47 Bd de l'Hôpital, Paris 75013, France.

(Accepted 18 May 1976.) left half of a drawing which, with the eyes closed, was done in full. We decided, therefore, to reinvestigate the problem. Patients with focal brain lesions were given a task requiring exploration of space, first without visual control then under visual control.

\section{METHOD}

\section{PATIENTS}

Twenty control and 91 brain-damaged subjects were used in the experiment. All subjects were right handed. The control group comprised personnel in the hospital and patients hospitalised for peripheral nerve lesions not affecting strength or sensation in the upper limbs. Unselected patients with unilateral focal brain lesions formed the pathological group. These patients were divided into four groups according to the cerebral hemisphere affected and the presence or absence of a visual field defect: left-sided group without visual field defect $(\mathrm{L}-)$, left-sided group with visual field defect $(\mathrm{L}+)$, right-sided group without visual field defect $(\mathrm{R}-)$, right-sided group with visual field defect $(R+)$. The four pathological groups were balanced with regard to age, educational background, nature, and duration of lesion. The principal features of the five groups are given in Table 1. For each brain-damaged subject, the following clinical features were recorded if present: unilateral pyramidal tract signs, unilateral somatosensory deficit, aphasia, severity of visual field defect, and 
TABLE 1

MAIN CHARACTERISTICS OF FIVE GROUPS

\begin{tabular}{|c|c|c|c|c|c|c|c|}
\hline & \multirow{2}{*}{$\begin{array}{c}\text { Age } \\
(\text { mean and range) } \\
(y r)\end{array}$} & \multicolumn{2}{|c|}{ Aetiology } & \multicolumn{2}{|c|}{ Age of lesion } & \multicolumn{2}{|c|}{$\begin{array}{c}\text { Unilateral } \\
\text { spatial neglect }\end{array}$} \\
\hline & & $C V A$ & Other & $\leqslant 3$ months & $>3$ months & Major & Minor \\
\hline $\begin{array}{l}\text { Controls } \\
(20 \mathrm{Ss})\end{array}$ & $\begin{array}{c}46 \\
(28-71)\end{array}$ & & & & & & \\
\hline $\begin{array}{c}\mathrm{L}- \\
(20 \mathrm{Ss})\end{array}$ & $\begin{array}{c}48 \\
(18-69)\end{array}$ & 11 & 9 & 13 & 7 & 0 & 0 \\
\hline $\begin{array}{c}\mathrm{L}+ \\
(20 \mathrm{Ss})\end{array}$ & $\begin{array}{c}49 \\
(21-78)\end{array}$ & 14 & 6 & 13 & 7 & 1 & 6 \\
\hline $\begin{array}{c}R- \\
(27 \mathrm{Ss})\end{array}$ & $\begin{array}{c}50 \\
(32-70)\end{array}$ & 15 & 12 & 18 & 9 & 2 & 3 \\
\hline $\begin{array}{c}R+ \\
(24 \text { Ss) }\end{array}$ & $\begin{array}{c}52 \\
(29-70)\end{array}$ & 14 & 10 & 17 & 7 & 8 & 2 \\
\hline
\end{tabular}

Lesions were considered as 'dating from more than three months' if an ischaemic vascular accident occurred at least three months previously or a space-occupying lesion removed at least three months previously.

CVA = cerebrovascular accident.

unilateral spatial neglect. With regard to the latter, we differentiated: (1) neglect affecting daily activities (major neglect); (2) neglect shown only in drawing or writing tasks (minor neglect).

\section{PROCEDURE}

The subject was seated facing a teletype connected to a PDP 10 computer. The teletype keyboard was 30 $\mathrm{cm}$ wide and $12 \mathrm{~cm}$ deep; it was situated $80 \mathrm{~cm}$ above the ground level. The distance from the subject was such that, laterally, the keyboard subtended $25^{\circ}$ of the visual field. The keys to the right of the keyboard midline - and of the subject's axis of vision-were considered as 'right-sided'; the keys to the left of the midline were considered as 'left-sided'. There were 26 'right-sided' keys and 26 'left-sided' keys.

The subject walked into the laboratory in such a way that he could not see the keyboard. He was blindfolded and seated in front of the teletype. Then the examiner took the subject's hand (the one he was going to type with) and had him explore tactually the limits of the keyboard. The subject was told 'to tap the keys all over the keyboard as quickly as possible in any manner he wished'. When 200 keys had been tapped, the computer indicated how many right- and left-sided keys had been tapped. At the conclusion of the test, the blindfold was removed and the subject was asked to perform the same task under visual control.

The subject used the hand homolateral to the brain lesion. Ten control subjects tapped with their right hand and 10 with their left.

\section{DATA ANALYSIS}

The asymmetry between the numbers of left-sided and right-sided keys tapped during the test was used to measure tendencies for either right- or left-sided neglect. As, in a symmetrical exploration, 100 keys were tapped on each side of the keyboard, the deviation from 100 was used. Arbitrarily, this numberwe shall henceforth use the notation RLI (right/left imbalance)-was positive when the subject tapped more keys on the left than on the right and negative in the reverse condition. Thus, a RLI of +40 indicated that 60 keys had been tapped on the right side and 140 on the left (a tendency for spatial neglect of the right side); a RLI of -40 indicated that 60 keys had been tapped on the left side and 140 on the right (a tendency for spatial neglect of the left side). For each subject there were two values of RLI, one obtained with blindfold $\left(\operatorname{RLI}_{A}\right)$ and one without blindfold $\left(\mathrm{RLI}_{\mathrm{B}}\right)$.

The two control subgroups did not differ one from another with regard to $\operatorname{RLI}_{\mathrm{A}}(t: 0.91 ; \mathrm{NS})$ and $\mathrm{RLI}_{\mathrm{B}}$ $(t: 1.39$; NS). They were therefore combined in a single group. Each brain-damaged group was compared with the control group with regard to each of the two variables. In addition, $\mathrm{RLI}_{\mathbf{A}}$ was compared with RLI $_{B}$ within each group.

\section{RESULTS}

The findings of the study are shown in Fig. 1. With regard to the first part of the experiment (tapping 
blindfolded), group $\mathrm{R}$ differed from the control group in that its $\mathrm{RLI}_{\mathrm{A}}$ was lower $(t: 3.59 ; \mathrm{P}<0.001)$. No significant difference was found for the three other brain-damaged groups.

With regard to the second part of the experiment (tapping without blindfold), groups $\mathrm{L}-$ and $\mathrm{R}-\mathrm{did}$ not differ from controls, while group $\mathrm{L}$ - and $\mathrm{R}$ did so. $\mathrm{RLI}_{B}$ was higher in group $\mathrm{L}$-- than in controls $(t: 2.25 ; \mathrm{P}<0.05)$ and lower in group $\mathrm{R} \cdots(t: 3.73$; $\mathrm{P}<0.001$ ).

When $\mathrm{RLI}_{A}$ and $\mathrm{RLI}_{\mathrm{B}}$ were compared with each other, no difference was found in the control group and group L . By contrast, there was a significant difference in the three other brain-damaged groups (Fig. 1).

These data indicate that, while normal subjects and group L explored the keyboard symmetrically in both experimental conditions, the three other groups did not. Patients with right hemisphere lesions and full visual fields actually demonstrated left-sided neglect when blindfolded. On the other hand, in patients with visual field defect, regardless of side of lesion, there was neglect (contralateral to the cerebral lesion) when the exploration was visually controlled.

To assess the frequency of marked neglect in the different groups, the number of patients in whom right/left imbalance scores were outside the normal range was determined (Table 2). The figures are in accord with the trends which have been described. In addition, two further points may be made: (1) the frequency of severe neglect appears to have been higher in right than in left hemispheric damage; $(2)$ in patients with right-sided lesions there was some overlap of the opposite trends of groups $\mathrm{R}-$ and $\mathrm{R}-$, as three patients in group $\mathrm{R}$ - neglected when blindfolded, while four patients in group $R$ neglected when not blindfolded. In groups $\mathrm{R} \cdots$ and $\mathrm{L}-$, marked asymmetries, as defined in Table 2 were found

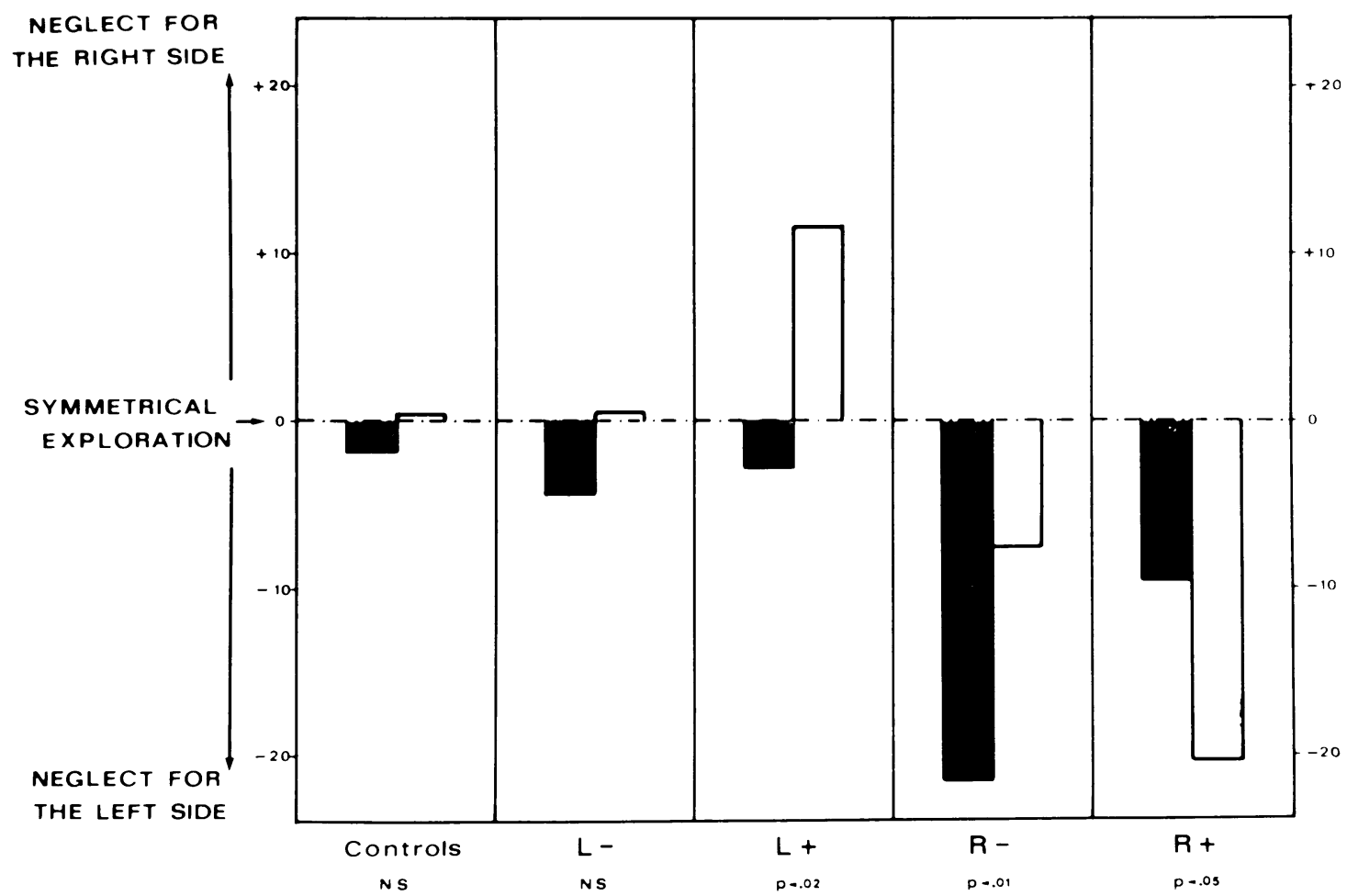

FIG. 1 Right left imbalance scores ( $R L I)$ obtained in the two experimental conditions, with blindfold (black columns) and without blindfold (white columns). The dotted line $(R L I=0)$ corresponds to an ideal symmetrical exploration. Positive scores indicate a tendency for right-sided neglect, negative scores a tendency for left-sided neglect. In each group, the scores obtained in the two experimental conditions were compared one to another by a paired data test. The significance of the differences is indicated below. 
mainly in those patients who were observed clinically to demonstrate neglect (Table 3). Apart from this finding, no significant relationship existed between the different clinical signs and the two figures measuring right/left imbalance.

\section{DISCUSSION}

Results will be discussed separately for patients with right-sided lesions and no visual field defect and for patients with a visual field defect.

PATIENTS WITH RIGHT-SIDED LESIONS AND NORMAL VISUAL FIELDS

When blindfolded, these patients, as a group, demonstrated left-sided defect in space exploration, while

TABLE 2

NUMBER OF SUBJECTS, DEMONSTRATING MARKED ASYMMETRY IN THE TWO EXPERIMENTAL CONDITIONS

\begin{tabular}{|c|c|c|c|c|c|}
\hline & & \multicolumn{4}{|c|}{ Asymmetry indicating } \\
\hline & & \multicolumn{2}{|c|}{$\begin{array}{l}\text { Left-sided neglect } \\
(\text { no. }) \quad(\%)\end{array}$} & \multicolumn{2}{|c|}{$\begin{array}{l}\text { Right-sided neglect } \\
\text { (no.) }\end{array}$} \\
\hline \multicolumn{6}{|c|}{ Blindfold } \\
\hline L - & (20) & 2 & 10 & 1 & 5 \\
\hline $\mathbf{L}+$ & (20) & 1 & 5 & 1 & 5 \\
\hline $\mathbf{R}-$ & (27) & 9 & 33 & 0 & \\
\hline $\mathbf{R}+$ & (24) & 3 & 12 & 1 & 4 \\
\hline \multicolumn{6}{|c|}{ No blindfold } \\
\hline L- & (20) & 1 & 5 & 0 & \\
\hline $\mathbf{L}+$ & (20) & 0 & & 4 & 20 \\
\hline $\mathbf{R}-$ & (27) & 4 & 14 & 0 & \\
\hline $\mathbf{R}+$ & (24) & 9 & 37 & 0 & \\
\hline
\end{tabular}

A subject was said to neglect markedly one side when the number of keys he had tapped on that side of the keyboard was lower than the lowest number observed in normal subjects.

\section{TABLE 3}

DISTRIBUTION OF PATIENTS ACCORDING TO PRESENCE OR ABSENCE OF CLINICAL SIGNS OF NEGLECT AND TO PRESENCE OR ABSENCE OF MARKED ASYMMETRY IN SECOND PART OF EXPERIMENT (WITHOUT BLINDFOLD)

\begin{tabular}{lccc}
\hline & & Clinical signs of neglect \\
\cline { 1 - 3 } $\begin{array}{l}\text { Marked asymmetry in } \\
\text { experiment (no blindfold) }\end{array}$ & & + & \\
& + & 11 & 2 \\
& - & 6 & 25 \\
\hline
\end{tabular}

Data are pooled for groups $\mathbf{R}+$ and $\mathbf{L}+$. A significant correlation exists between the two ways of evaluating neglect (Chi square: 13.8; $\mathbf{P}<0.001$ ). they did not do so once the blindfold was removed. The first question which may be raised is whether or not this abnormal behaviour was a genuine neglect. The phenomenon might have reflected a kind of 'motor inertia' with the subject tapping preferentially in the right half of space (the right hand was used) rather than across the midline. The whole test was therefore repeated with the left hand in eight subjects of the group: performances did not change significantly, thus satisfying this possible objection. On the other hand, the defective exploration could be regarded as due to a disturbance in muscle tone facilitating movement of the upper limbs toward the side of the lesion. Although this possibility cannot be definitively excluded, it seems unlikely, as, to our knowledge, nothing of this kind has been reported in focal brain pathology.

Thus, there does seem to be a kind of spatial neglect which develops (or is reinforced) when visual inputs are cut off. No satisfactory explanation was found to account for this unexpected finding. Some general disorder affecting the orientation of the whole body ine space and confined to the dark, similar to what has been described in monkeys with parietal lesions by Hartje and Ettlinger (1973), might be responsible.

\section{PATIENTS WITH VISUAL FIELD DEFECT}

In patients with a visual field defect there was a ten dency to neglect that part of the experimental extrapersonal space which was contralateral to the brain lesion. Although present in lesions of either side of theo brain, the tendency was more marked in some subjects with right hemispheric damage, an observation consistent with those of others (Gainotti, 1968; de Renzi et al., 1970; Albert, 1973).

Most remarkable was the absence, in most of these subjects, of neglect in the dark. This finding suggests that unilateral defect in manual exploration of space is induced by vision and that consequently space representation per se is not altered in unilateral spatial neglect. Such a conclusion is in contrast with that reached by de Renzi et al. (1970). These authors found that patients with visual field defect neglected when searching for a marble in a maze hidden by a curtain; in this experiment, however, the patient kept the eyes open and thus could in some way be influenced by visual inputs. How can the introduction of vision induce a spatial neglect? As patients with spatial neglect demonstrate a lack of incitement to look toward the neglected side (Chédru et al., 1973), the assumption is made that a defect in oculomotor scanning is the primary disorder. Damage of the parietal lobe would play a critical role in this respect. Mountcastle et al. (1975) have demonstrated the existence, in the monkey parietal association cortex, of cells which direct 
'visual attention to and exploration of the immediately surrounding extrapersonal space'. Disruption of these sets of cells would cause ignorance of the contralateral space provided visual inputs are present (the cells being mainly visual in nature, no neglect is expected in the dark).

Kinsbourne recently demonstrated that the direction in which normal people look while thinking reflects the lateralisation of the underlying cerebral activity (Kinsbourne, 1972). If an oculomotor imbalance is playing a role in neglect, the nature of the task - that is, the laterality of the hemisphere involved in that task - should influence the intensity of the phenomenon. The studies of Leicester et al. (1969) as well as personal (still unpublished) data suggests that this is indeed the case.

One can speculate that gaze deviation is more marked in the case of right-sided lesions because of an inborn cerebral organisation making, in right-handed subjects, gaze displacements easier to the right than to the left. Developmental studies have demonstrated that the tonic neck reflex is to the right in newborns who will become right-handed whereas it is not in most of the others (Gesell and Ames, 1947). As head turning and eye movements appear to belong to the same system (Bizzi et al., 1971), an identical predisposition might exist with regard to eye movements. These considerations are, of course, not inconsistent with the hypothesis that spatial neglect and other aspects of unilateral inattention are related to the disruption of a corticolimbic reticular activating loop (Watson et al., 1973).

There remains the question of why patients who could build up a normal inner representation of space from past visual experiences and ongoing kinaesthetic information, were so sensitive to visual inputs. The dominant position of vision among the senses probably plays a major role. In fact, normal subjects given visual information contradictory to tactile or auditory information always rely upon vision (Rock and Harris, 1966; Pick et al., 1969).

Whatever the pathophysiology of the syndrome, the present conclusions have practical implications: the rehabilitation of severe and lasting spatial neglect will be facilitated by having the patients perform the same exploratory task initially without and then under visual control.

We wish to thank Mrs. E. Andreewsky for computational assistance, Professor F. Lhermitte for helpful criticism and Professor A. L. Benton for comments on both the form and content of the paper.

\section{REFERENCES}

Albert, M. (1973). A simple test of visual neglect. Neurology (Minneap.), 23, 658-664.

Benton, A. L. (1969). Disorders of spatial orientation. In Handbook of Clinical Neurology, vol. 3, pp. 212228. Edited by P. J. Vinken and G. W. Bruyn. North Holland: Amsterdam.

Bizzi, E., Kalil, R. E., and Tagliasco, V. (1971). Eye-head coordination in monkeys: evidence for centrally patterned organization. Science, 173, 452-454.

Brain, W. R. (1941). Visual disorientation with special reference to lesions of the right cerebral hemisphere. Brain, 64, 244-272.

Chédru, F., Leblanc, M., and Lhermitte, F. (1973). Visual searching in normal and brain damaged subjects. Contribution to the study of unilateral inattention. Cortex, 9,94-111.

de Renzi, E., Faglioni, P., and Scotti, G. (1970). Hemispheric contribution to exploration of space through the visual and tactile modality. Cortex, 6, 191-203.

Gainotti, G. (1968). Les manifestations de négligence et d'inattention pour l'hémispace. Cortex, 4, 64-91.

Gesell, A., and Ames, L. B. (1947). The development of handedness. Journal of Genetic Psychology, 70, 155-175.

Hartje, W., and Ettlinger, G. (1973). Reaching in light and dark after unilateral posterior parietal ablation in the monkey. Cortex, 9, 344-354.

Kinsbourne, M. (1972). Eye and head turning indicate cerebral lateralization. Science, 176, 539-541.

Leicester, J., Sidman, M., Stoddart, L. T., and Mohr, J. P. (1969). Some determinants of visual neglect. Journal of Neurology, Neurosurgery, and Psychiatry. 132, 580-587.

McFie, J., Piercy, M. F., and Zangwill, O. L. (1950). Visuo-spatial agnosia associated with lesions of the right cerebral hemisphere. Brain, 73, 167-190.

Mountcastle, V. B., Lynch, J. C., Geogopoulos, A., Sakata, H., and Acuna, C. (1975). Posterior parietal association cortex of the monkey; command functions for operations within extrapersonal space. Journal of Neurophysiology, 38, 871-908.

Oxbury, J. M., Campbell, D. C., and Oxbury, S. M. (1974). Unilateral spatial neglect and impairments of spatial analysis and visual perception. Brain, 97, 551-564.

Pick, H. L., Warren, D. H., and Hay, J. C. (1969). Sensory conflict in judgments of spatial direction. Perception and Psychophysics, 6, 203-205.

Rock, I., and Harris, C. S. (1966). Vision and touch. Scientific American, 96-104.

Semmes, J., Weinstein, S., Ghent, L., and Teuber, H. L. (1955). Spatial orientation in man after cerebral injury: analysis by locus of lesion. Journal of Psychology, 39, 227-244.

Watson, R. T., Heilman, K. M., Canthen, J. C., and King, F. A. (1973). Neglect after cingulectomy. Neurology (Minneap.), 23, 1003-1007. 